First Peoples Child \& Family Review

A Journal on Innovation and Best Practices in Aboriginal Child Welfare Administration,

Research, Policy \& Practice

\title{
Going Back to the Roots: Using the Medicine Wheel in the Healing Process
}

\section{Robert C. Twigg and Thomas Hengen}

Volume 4, Number 1, 2009

URI: https://id.erudit.org/iderudit/1069345ar

DOI: https://doi.org/10.7202/1069345ar

See table of contents

\section{Publisher(s)}

First Nations Child and Family Caring Society of Canada

\section{ISSN}

1708-489X (print)

2293-6610 (digital)

Explore this journal

Cite this article

Twigg, R. \& Hengen, T. (2009). Going Back to the Roots: Using the Medicine Wheel in the Healing Process. First Peoples Child \& Family Review, 4(1), 10-19. https://doi.org/10.7202/1069345ar

\section{Article abstract}

This article describes Building A Nation, a store front program located in the heart of the core neighbourhood (west side) of Saskatoon and its use of the Medicine Wheel in providing a blend of traditional and western support services including supportive therapy to those who come through its doors. This article begins with a discussion of the need for culturally safe and competent counselling programs and how Building A Nation meets that need. Following this the paper discusses the Medicine Wheel and how the Medicine Wheel is used in the Building A Nation program. This article is a step toward completing the recommendation by the Aboriginal Healing Foundation that Building A Nation "provide more clarity about how western and traditional healing methods complement each other or blend together (Aboriginal Healing Foundation 2006, p. 275).
This document is protected by copyright law. Use of the services of Érudit (including reproduction) is subject to its terms and conditions, which can be viewed online.

https://apropos.erudit.org/en/users/policy-on-use/ 


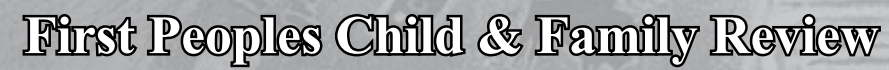

A Journal on Innovation and Best Practices in Aboriginal Child Welfare Administration, Research, Policy \& Practice

Volume 4, Number 1, 2009, pp. 10-19

\title{
Going Back to the Roots: Using the Medicine Wheel in the Healing Process
}

\author{
Robert C. Twigg a and Dr. Thomas Hengen ${ }^{b}$
}

\begin{abstract}
a PhD, Associate Professor, Faculty of Social Work, University of Regina, Regina, Saskatchewan, Canada

${ }^{\mathrm{b}}$ Executive Director, Building A Nation Family Healing Centre, Inc., Regina, Saskatchewan, Canada
\end{abstract}

\section{The Need for Culturally Safe and Competent Counselling Services}

Writing about the effects of racism on mental health services in the United States and focusing on the AfroAmerican population, Rollock and Gordon (2000) state "As a belief and an action potential, racism can erode the mental health status of its individual victims and dominate the institutional and cultural mechanisms through which it operates" (p.6). They further go on to list the areas racism influences as the definition of mental health and pathology, the explanation of the etiology of mental health problems, their evaluation and treatment and the institutional structure in which metal health services are delivered, including the training of mental health professionals (p.6-7).

Cultural safety and cultural competence, which have been identified as key components in providing services to Aboriginal People (NAHO, 2009), are attempts to counter the influence of racism on mental health services. Cultural safety refers to the need to move "beyond the concept of cultural sensitivity to analyzing power imbalances, institutional discrimination, colonization and colonial relationships as they apply to health care" (NAHO, p.3). Cultural competence is defined as "a set of congruent behaviours, attitudes, and policies that come together in a system, agency, or among professionals and enable that system, agency, or those professionals to work effectively

\footnotetext{
Questions or correspondence concerning this article may be addressed to:

Robert.twigg@uregina.ca

ortshengen@shaw.ca
}

\begin{abstract}
This article describes Building A Nation, a store front program located in the heart of the core neighbourhood (west side) of Saskatoon and its use of the Medicine Wheel in providing a blend of traditional and western support services including supportive therapy to those who come through its doors. This article begins with a discussion of the need for culturally safe and competent counselling programs and how Building A Nation meets that need. Following this the paper discusses the Medicine Wheel and how the Medicine Wheel is used in the Building A Nation program. This article is a step toward completing the recommendation by the Aboriginal Healing Foundation that Building A Nation "provide more clarity about how western and traditional healing methods complement each other or blend together (Aboriginal Healing Foundation 2006, p. 275).
\end{abstract}

in cross cultural situations" (U.S. Department of Health and Human Services, 2007 cited in NAHO, 2009, p.3). The U.S. Department of Health also states that "the seven domains (of cultural competence) are: organizational values, governance, planning and monitoring/evaluation, communication, staff development, organizational infrastructure, and services/interventions (U.S. Department of Health and Human Services, 2007, cited in NAHO, 2009, p.3).

Research shows that the lack of cultural safety and cultural competence leads to problems such as incomplete assessments, incorrect diagnoses, inadequate or inappropriate treatment, failed therapeutic alliances, high rates of noncompliance, reluctance to visit mainstream health facilities even when service is needed, and feelings of fear, disrespect and alienation (Kirmayer, et. al., 2003, p. 153; NAHO, 2003, cited in NAHO 2009). According to some researchers (Sue, 1981; Trimble and Fleming, 1990; and More, 1985, all cited in McCormick, 1996) Aboriginal peoples tend not to use the mental health services provided by the mainstream culture, and of those who do, approximately half drop out after the first session. 
In the context of the population served by Building $A$ Nation (BAN) a culturally sensitive and competent mental health program requires, among other things, that service providers recognize the impact of residential schools and the other forms of cultural assimilation attempted by the dominant culture to deal with the "Indian problem" on Aboriginal People today.

McCormick (1996, p.163) reports that Aboriginal People experience the same mental health problems as do their non-Aboriginal neighbours. In addition he reports that rates of suicide, depression, substance abuse, and domestic violence may be significantly higher among aboriginal peoples. Recent statistics indicate that the suicide rate among Aboriginal People is twice that of the Canadian population (Government of Canada, 2006, cited in Kirmayer. et al. 2007, p.13). These statistics point out the need for a counselling program that is both accessible and acceptable to Aboriginal Persons needing assistance who will not be able to benefit from counselling approaches that are not grounded in aboriginal beliefs and culture.

One example of the lack if fit between Aboriginal people and counselling services that are not culturally safe and competent is the cultural differences in understanding the causes and solutions for mental health problems. Traditional western thinking viewed mental health issues as a form of individual illness to be "cured" by trained experts. The recipient of services was viewed as an object on which healing activities were done, rather than a partner in the healing process. While current thinking in western therapy has moved from that model to a more egalitarian one in which the client is the expert and the therapist facilitates the healing process, the perception still exists that western therapies are based on the doctor patient, medical model approach.

The mainstream approach to the provision of mental health services may also view the mental health issue as a single, isolated one, failing to place it in the context of the entire life of the client including his/her stage of development and place in the community. This linear, isolating approach to mental health is at odds with the traditional First Nations approach with its focus on the Medicine Wheel and the belief that physical and mental health are the result of leading a balanced life.

This article will show how one program, Building A Nation, strives to meet the needs of a population of marginalized people, mainly Aboriginal, living in inner city Saskatoon. The article will demonstrate how using the Medicine Wheel as an organizing tool achieves this goal.

\section{Building A Nation}

\section{History and Development}

Building A Nation Family Healing Centre, Inc. was registered as a non-profit organization in 1998 and has been funded by the Aboriginal Healing Foundation. Currently BAN is funded primarily by the Aboriginal Healing Foundation with additional funding from some other national sources. BAN receives no funding from either the provincial or municipal governments.

BAN was founded by Mr. Glen McCallum and Dr. Tom Hengen. Both men, one Aboriginal and one non-Aboriginal, were working independently in different Aboriginal communities, one urban and one rural. They met and developed a shared vision of developing a program to serve those who live in the core neighbourhood of Saskatoon; a neighbourhood that is under serviced to the point of being neglected; its residents live in conditions of poverty and its accompanying challenges literally a short walk from thriving downtown Saskatoon.

Saskatoon's core neighbourhood is largely populated by people who came to the city from reserves and small rural communities across Saskatchewan because of the lack of jobs and resources for children and families in those areas. They were in effect forced from their home communities because of poverty, depressed circumstances, and the lack of resources that accompanies those conditions. In spite of their hope, and the lifestyle promised by city life, when they arrived on the west side of Saskatoon they found themselves in circumstances much like those they sought to leave.

For those living on reserves this migration was made both possible and necessary by changes in Federal Indian Policy. Prior to 1952 persons living on reserve were allowed to leave the reserve only with the permission of the Indian Agent. They were also not allowed to conduct business transactions outside the reserve. Records kept by the Federation of Saskatchewan Indian Nations (FSIN) indicate that between the start date of urban migration in1952 and the early1960's the number of Aboriginal Persons incarcerated in Canada effectively doubled (Michael, H., personal communication, June 5th, 2009).

For many of those leaving reserves and small rural communities the move from reserve to city, spurred by both opportunity and necessity, was like moving to a foreign country. The reserves were under the jurisdiction of the Federal government and the west side of Saskatoon was under the jurisdiction of city and provincial governments which ultimately proved to be no more capable of seeing the condition of the Aboriginal population improve than the Federal government had been. Speaking of health care services Evans, Sookraj, Berg \& The Okanagan Urban Aboriginal Health Research Collective (2006, cited in Kurtz, et. al., 2009, p.54) state "the provision of services for urban Aboriginal people is impeded by the continuing rural/reservation orientation of many Euro-Canadian and Aboriginal policy makers." 
While the core area is largely populated by Aboriginal people, McCallum and Hengen recognized that they were not the sole residents of the neighbourhood; thus if they were to develop a program that would meet the needs of the people in that area it would be necessary to offer a service that would respect differing cultural and spiritual orientations. It is estimated that $90 \%$ of those who currently use BAN are Aboriginal Persons. Most of the others come to BAN because they are a relationship with a person of Aboriginal descent (Tom Hengen, personal communication, March 5, 2009).

BAN is headed by a Board of Directors made up of First Nations (Cree and Saulteaux), Métis, Euro-Canadian, and mixed cultural background. The staff also reflects this cultural mix. All are dedicated to restoring "the traditional Aboriginal way of perceiving and responding to experience as a remedy against the deleterious effects of enforced cultural assimilation - social disorientation and cultural deprivation, both of which are known to be healthrelated jeopardy conditions" (Building A Nation, 1998, p.3). The board members acknowledge that they "had to learn to work out our differences and how to bridge the gap. When we formed our board we did not see eye to eye, but it worked. We learned about each other. We learned about each other's culture" (The Times Observer, cited in Aboriginal Healing Foundation, Volume 2, 2006, p. 272). This learning process has been a part of all aspects of the development of the BAN program.

While not all of those who work at BAN are of Aboriginal origin, all share the vision of the program and all have, or have developed, traditional environmental knowledge (TEK). TEK is defined as knowledge accumulated through

\begin{abstract}
"Time spent living on the land. It encompasses all aspects of the environment -biophysical, economic, social, cultural, and spiritual - and sees humans as an intimate part of it, rather than as external observers or controllers. TEK is part of the collective memory of a community, and is passed on orally through songs and stories as well as through actions and observations." (Environment Canada, n.d.p. 1).
\end{abstract}

In the case of BAN staff TEK include knowledge of the core city environment.

The mission statement of BAN reads:

"Build our Nation, Canada, as a community of citizens living in the spirit of a 'cultural mosaic' in harmony together. Our logo portrays this. Our company's structure, comprised of First Nations, Métis, and mainstream people demonstrates this. It is our purpose to honour real differences as gifts of diversity and to achieve harmony and integrity by commitment to common goals." (Building A Nation, 1998. p.2)
The BAN logo is the creation of Gary Natomagan, a recognized Cree artist who grew up near Pinehouse Lake, Saskatchewan. The left side of the logo represents the Métis community, the right the First Nations of Canada. The name Building A Nation reflects how the goal of BAN, building a social nation, differs from the goals of the Canadian government, the Federation of Saskatchewan Indian Nations (FSIN) and the Métis Nation Society (MNS), all of which have stated goals of building political nations.

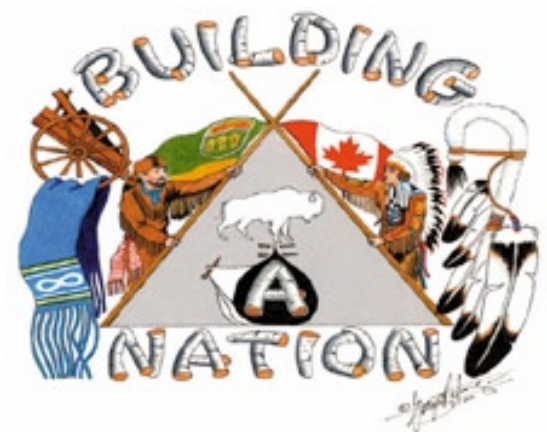

\section{$B A N$ program}

In the funding application to the Aboriginal Healing Foundation the BAN program is described as follows:

\begin{abstract}
"To provide clinical and traditional counselling services, as well as child custody, justice system, and social assistance program support to individuals and specific interest groups. Clinical services are provided by a registered counselling psychologist, a certified mental health therapist, whose practices are done in the four directions worldview, providing counselling to women, children, men and couples. Crisis services are provided by trained crisis intervention counsellors of Aboriginal descent. We have a traditional therapist who provides traditional ceremonies and practices as well as counselling to our clients and survivors. (Waldram, 2005, p.4)
\end{abstract}

A subsequent application for renewed funding indicated a continuing commitment to this agenda with additional emphasis on dealing with issues related to Indian Residential School survivors.

The final report of the Aboriginal Healing Foundation indicates that "in addition to individual and group counselling, healing activities include traditional celebrations and ceremonies, continuing support (e.g. drop in center, client advocacy for those involved in the justice system, child custody) and social gatherings (Aboriginal Healing Foundation, 2006, p. 265). Client skill development programs have included programs titled "Aboriginal Parenting Skills," and "Aboriginal Counselling and Cultural Education Strategies and Systems (A.C.C.E.S.S.)." The counselling component of the youth program has 
subsequently been offered as "Medicine Wheel Counselling and Case Management" at four levels of competency by the sister organization, Building A Nation Training Institute, Inc., a private vocational school registered with Saskatchewan Learning (the Saskatchewan government ministry responsible for education).

A ten week youth oriented theatre production program called "Circle of Voices" designed to actualize theatrical talent in young people and thus help in nation building by using the healing power of the arts to tell the story of their struggle towards healthy lifestyle in Canadian mainstream culture was offered. The 'Circle of Voices' initiative has developed into the very successful Saskatchewan Native Theatre Company which enhances the core neighbourhood with a live-stage theatre that regularly mounts productions, written, acted, produced, and directed by Aboriginal community members; serving both the core neighbourhood and the greater Saskatoon community while honouring their cultural heritage.

\section{Provision of Service}

The Aboriginal orientation of BAN is obvious when one is greeted by the scent of sweetgrass as one walks through the door. One client described how, when he entered BAN and smelled the sweetgrass, he felt relaxed. "It's hard to explain but when you come into a place with sweetgrass and the pictures (native art) on the walls it triggers something in you. ... This is where you belong" (D. Michel, 2007, Personal communication).

The person staffing the front desk has knowledge of the support services available to most visitors as well as contact persons within the Saskatchewan Department of Community Resources, the city police, and medical services. Visitors are greeted in a pleasant, supportive manner while sufficient information is gathered to determine their needs. A client describes the importance of this initial contact this way "Its the atmosphere when you come in here, even the woman at the front desk, she smiles at you and talks to you nice" (D. Michel, 2007, Personal communication).

Clients of BAN can move beyond the waiting room into a common room where they can sit and visit with each other and the staff in a very informal way. An appointment is not needed to access this space nor is there any expectation that those in the room will seek further service while they are there. This common room serves as a safe place for those who need to retreat from life in the core neighbourhood and those who seek positive peer support. Clients can also wait in this area for their counsellor and can spend time there after visiting the counsellor.

As one counsellor put it "this is a safe area for now and sometimes they (clients) need safe areas. They can come in and be part of the family. So they are welcome" (C. Crevier, 2007, Personal communication). A client described using the common room to escape from his former friends; a group that included drug dealers, alcoholics and others living on the street: "It was more of a sanctuary. .. I'd say to my friends I'm gonna hang out there and meet people, meet different people. Now I know a lot of people and I know myself more" (D. Michel, 2007, Personal communication).

The counsellors at BAN are frequently described as "rented" uncles or aunts who respectfully walk with their clients during the changes that they must make in their lives.

\section{Recipients of Services}

Off-reserve communities are among the largest and fastest growing Aboriginal communities in Canada with over 70 per cent of Aboriginal people living in urban areas (Statistics Canada, 2006, cited in Kurtz, et. A1, 2009, p. $54)$. For the population served by BAN as well as for Aboriginal people across Canada and Indigenous Peoples around the world, colonial policies and practices have had a multigenerational impact. These policies and their sequelae have resulted in problems such as homelessness, addictions, poverty, domestic violence, family dysfunction, and a lower health status for many Aboriginal people. A recent study in Saskatoon measured the health differences in low and high income areas of the city and found residents of the poorer areas, of which the core neighbourhood was one, had statistically significantly higher incidences of suicide attempts, mental disorders, injuries and poisonings, diabetes, chronic obstructive pulmonary disease, coronary heart disease, chlamydia, gonorrhoea, hepatitis $\mathrm{C}$, teen birth, low birth weight, infant mortality and all cause mortality (Lemstra, Neudorf, \& Opondo, 2007). The inability of existing social services to meet this need highlights the need for the services offered by BAN.

While the BAN program has not produced detailed demographic information about those it serves, it is estimated that about 1,000 individual files are active every year. As these files are in the name of a single person the actual number of those served is significantly higher as usually nuclear and extended family members are also served (T. Hengen, Personal communication, May 28, 2009). Waldram, et. Al (2005) interviewed 18 participants of the BAN program and offered the following profile of clients:

- Mean age 41

- $72 \%$ male

- $78 \%$ single

- $61 \%$ caregivers for children in their home

- $44 \%$ spoke no aboriginal language

- $90 \%$ of those who spoke an aboriginal language spoke Cree 


\section{Going Back to the Roots: Using the Medicine Wheel in the Healing Process}

- $76 \%$ had little or no knowledge of their aboriginal heritage

- $50 \%$ had attended residential school

- $61 \%$ had experienced foster care

- $72 \%$ had been adopted

While this profile was drawn from a small opportunistic sample it provides a picture of those who make use of the services BAN provides.

The final report of the Aboriginal Healing Foundation offers this description of the BAN clientele, based on a study of 432 clients:

- $70 \%$ had experienced physical abuse

- slightly less than 50\% had suffered sexual abuse

- just over $30 \%$ had been incarcerated

- just over $20 \%$ were survivors of residential schools (Aboriginal Healing Foundation, Volume 2, 2006, p. 267).

While BAN is located in Saskatoon's core neighbourhood and the majority of its clients live in that area, the recipients of services come from throughout the city. As one counsellor pointed out, while the socioeconomic status may vary, the needs of all BAN clients are similar.

\begin{abstract}
"We've also had educators, counsellors, health professionals in different areas that come here that are not on the street. They are out there. They are doing. They are educating children. They are helping. They are out there in society. They meet society's norms. ... but they have similar problems with sexual abuse, physical abuse, and this and that in their developmental years. They come here; they face the same problems with alcohol abuse, drug abuse all the same. ... The Medicine Wheel helps them see where they are as an individual person. So they have to express their desire to do something, they have to know what they want to do, they have to know who they are, they have to know what they came from in order to go on." (C. Crevier. 2007, Personal communication)
\end{abstract}

\section{Medicine Wheel}

The Aboriginal world view is shaped by a sense of balance, interconnectedness, and transcendence (McCormick, 1996). A circular, rather than linear, way of thinking puts the focus of the world view on relationships and balance. From this perspective mental health can be understood as achieving a balance between the parts of the self - emotional, physical, mental and spiritual; finding one's place in relation to other human beings, finding one's place in relation to mother earth, and looking beyond oneself (Chansonneuve, 2007).
Montour, speaking from the twin perspectives of a person of Mohawk ancestry and a medical practitioner, says:

\begin{abstract}
"The Medicine Wheel concept from Native American culture provides a model for who we are as individuals. We have an intellectual self, a spiritual self, an emotional self, and a physical self. Strength and balance in all quadrants of the Medicine Wheel can produce a strong, positive sense of wellbeing, whereas imbalance in one or more quadrants can cause symptoms of illness. Addressing issues of imbalance can potentially diminish your patient's symptoms and enrich their quality of life." (Montour, 1996)
\end{abstract}

McCormick states "First Nations healing requires the individual to transcend the ego rather than strengthen it as Western counselling aims to do" (1996, p. 164). The Medicine Wheel represents this understanding to those who understand its meaning. The wheel represents both the connectedness and transcendence, while the four quadrants of the wheel represent the balance. The sense of community and transcendence also means that the Aboriginal person has the support of her/his community and is expected to provide support to others.

The use of the Medicine Wheel in this way is an example of holistic practice (Chansonneuve, 2007), a concept that in recent years had a strong influence on all forms of human services. Holistic practice can mean either an approach that takes into account the mental, physical, emotional, spiritual and social components of human functioning or as an umbrella term for alternative medical practice. In this article the former definition will be used.

While the holistic movement should be seen as having its roots in traditional Aboriginal teachings, within mainstream thought its roots come from the Social Work "person-in environment" paradigm which was rooted in the ecological and systems theories (Kemp, Whittaker, \& Tracy, 1997). The Person-In Environment paradigm reached its peak with the 1994 publication of "Person-in Environment System: The PIE Classification System for Social Functioning Problems" (Karls \& Wanderi, 1994). The PIE classification system with its focus on social functioning, environmental problems, mental health problems, and physical health problems (Karls \& Wanderi, p. 24) was heralded as the social work alternative to the DSM diagnostic system. More recently it has resurfaced in the Social Work literature under the titles resiliency and relational perspectives (Van Hook, 2009).

\section{The Medicine Wheel as Used at BAN}

As Bruyere states, teachings based on the Medicine Wheel have been "used to inform a multiplicity of cultural practices since time immemorial" (2007, p. 259), even physical activity (Lavallee, 2009). As the philosophical 


\section{First Peoples Child \& Family Review, Volume 4, Number 1, 2008}

and therapeutic paradigm for BAN, the Medicine Wheel is used as "a pedagogical tool for helping clients understand, visually as well as conceptually, how to lead a balanced and healthy lifestyle" (Waldram, 2005, p. 22). The Medicine Wheel serves to anchor the BAN program to the values of the traditional Aboriginal worldview as well as serving as a paradigm with which to integrate mainstream theories and techniques. At BAN the Medicine Wheel is used in many ways, including to:

- Organize human experience: By teaching clients as adult learners the Medicine Wheel view of human development, clients take cognitive ownership over their personal histories and begin to make predictions and form growth goals for themselves.

- Track human growth: Notably the longer-term effect of remedial therapies indicated in the case plan.

- As a general assessment tool by which to organize the client's medical and psychological (developmental) history.

- As a tool designed specifically for trauma assessment: Specifically to chart the impact of untreated Post Traumatic Stress Disorder symptoms (DSMIV-TR APA2002, p.463 etseq.) particularly trauma symptom sets unique to the Aboriginal population (Wesley-Esquimaux \& Smolewski, 2004).

- Decision making regarding the relative efficacy of remedial therapies.

- Psychological testing with a more relevant developmental \{dynamic\} view rather than a clinical snapshot or static view of the clients' condition.

- Case management: Organizing observable outcome target behaviours.

The version of the Medicine Wheel used at BAN is based on the Cree Medicine Wheel as persons of Cree background make up the largest percentage of the population in the neighbourhood being served as well as being the largest Aboriginal group in Saskatchewan.

\section{World view}

The worldview taught and modelled at BAN can best be described using the four directions of the Medicine Wheel:

- The West, childhood, springtime and emotional beginnings. It is represented by the beginning stage of learning and the earliest level of moral development, namely: Coercion/competition - authority or teacherdirected actions; the natural instinct to fill one's own needs is balanced by the need to comply with persons on whom one must depend (power/authority).

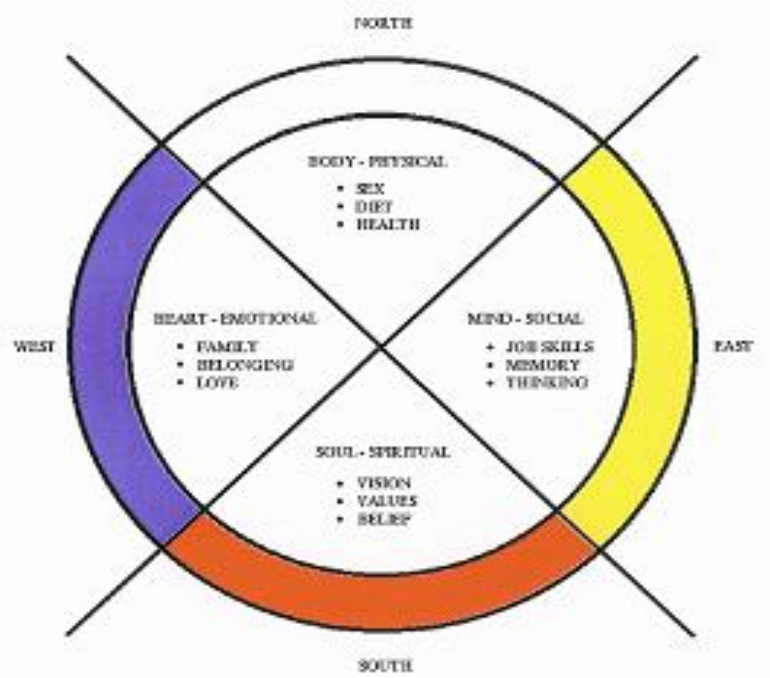

- The North, youth, summertime and physical maturity. It is represented by the next stage of learning from peers, and the next level of moral development which is: cooperation - peer directed actions; the natural instinct to develop one's own strengths leads to connecting with others who are close in age/stage to doing the same, as models of the next steps in development. Freedom requires and develops self reliance by gradual shifts from dependency to self-reliance.

- The East, adult, the time of harvest and mental maturity. It is represented by the next stage of learning as a self-directed learner, and the next level of moral development which is: Contribution - self directed actions.

- The South, elder, the time of spiritual maturity. It is represented by the last stage of learning as directed by one's values [the pipe and the medicine bundle] and the highest level of moral development which is: consecration - values-directed actions; giving completely (Hengen, 2006a, 2006b).

One counsellor describes the Medicine Wheel based approach to therapy in these terms:

They start filling in the four quadrants. They can see themselves as a whole person, what happened here (in childhood), what happened here (as a youth), that is happening here (as an adult), to make them who they are today. Then they say to themselves 'Well for this one I'm going to do this treatment or I'm gonna go to sweats, or go to a doctor or .... They know what it's about and they can see what it's about. Then the cultural content is really there for them to realize that this is who I am. I am still Native. I can be proud of 


\section{Going Back to the Roots: Using the Medicine Wheel in the Healing Process}

who I am. '... So they begin to heal themselves.... We (the counsellors) validate and then support them in their journey. They're the ones who are working. We are just sort of leaning posts along the way, or the cane." (C. Crevier, 2007, Personal communication)

\section{Animal Imagery}

A BAN counsellor described using a Medicine Wheel filled with animal images.

\begin{abstract}
"When we look at the eagle in the Medicine Wheel down here (south quadrant) because the eagle's way up there (pointing toward the ceiling) and he's got the whole view of what's down there and this is what, if we had that sort of view and look down on ourselves to see what all of our problems are and what we need to do about the healing process.
\end{abstract}

And then if you look at the bear (West quadrant), the emotional aspect. The bear protects her cubs. They are a ferocious animal when you try to take their cubs away from them. And if our parents were like the bear way back when there's no way we'd had residential schools. There was no way they'd of let us go there. ...

And we look at the buffalo (north quadrant). They're powerful animals. They were necessary for our survival, they gave us our life.

And when you look at the wolf (east quadrant) and how the wolf works in packs just like our men did in hunting. They worked in packs and they shared their kill. When the men came back from hunting it wasn't only the one who killed the deer who had the deer, it was shared with the whole camp. So my understanding of the Medicine Wheel concept is it is a holistic approach. It talks to the whole person." (F. Badger. 2007. Personal communication)

\section{Organizing Human Experience}

BAN offers a training program for its staff in the use of the Medicine Wheel. In the training literature the quadrants of the Medicine Wheel are used to organize human experience, specifically the four major factors thereof, which become the template for identifying types of needs and types of healing and helping services:

"The major factors of human experience included in the Medicine Wheel are:

- Emotional factors: these include the array of human feelings, of love, belonging, fear, joy and the like. Issues that began in childhood are often located in this quadrant as well.

- Physical factors: these include diet, health, sexual identity and maturity. Issues of addiction, chronic or acute stress symptoms and developmental issues of adolescence are placed in this quadrant.

- Mental/social factors: general intellectual ability, social skills, education, career development and interpersonal communication are included as mental abilities. Issues of spousal relationships, parenting, liaison with service and Crown agencies and adult education are generally placed in this quadrant.

- Spiritual/moral factors: moral values, respect, religious beliefs, and personal goals are included as matters of the spirit; spiritual or moral development is often plotted in this quadrant as the inventory of what the client respects enough to actually pursue as goals related to items in their 'respect' inventory." (Hengen, 2006a, p. 2)

\section{Human Growth}

Human growth can also be symbolized using the Medicine Wheel. In the BAN training manual this aspect of the Medicine Wheel is organized in this way:

- Childhood: the time when emotional conditions are developed and established within the person. This is called the spring-time of life; it is the start of growth toward full human experience. Healthy emotional bonding, learned by experience during childhood, is the foundation for good parenting in later life.

- Adolescence: the time when physical conditions are developed and established within the person. This is called the summer of life, the season of rapid physical growth; the body becomes mature during adolescence and the strengths or potentials for productivity are manifested. Acquiring impulse control is the key feature of adolescent development.

- Adult: the time of mental and social maturity. Education is completed or extended and careers are developed. This is the season of harvest that runs from early life to late in life, as does the need for hunting and gathering, or meaningful work for most persons, particularly those with large extended families. Besides emotional bonding, parenting skill is composed of a strong sense of what is socially healthy for children and families.

- Elder: the time of spiritual maturity. Completion of the human life cycle is realized by the fulfillment of goals and personal values lived out to some sense of completion. This is the winter of life when the person prepares to return to the earth mother for rest. The transmission of cultural traditions is one of the personal and family duties of elders. Presenting the model of personal integrity is one of the social responsibilities of elders (Hengen, 2006a, p. 2-3). 


\section{The Medicine Wheel As An Assessment Tool}

As stated earlier, the Medicine Wheel is used at BAN both to anchor the program to the values of the traditional Aboriginal worldview and to serve as a paradigm with which to integrate traditional and mainstream theories and techniques. One non Aboriginal counsellor described her use of the Medicine Wheel as a step in making her work more culturally competent (Thomas, 2006).

Clients of Aboriginal background are greeted and served at BAN through a tool that represents a worldview different from that of the western culture around them. The Medicine Wheel is a "cultural traditional model that they accept and it doesn't have to be forced on them because they accept it naturally especially if they are First Nation, Métis (they say). Well, this is mine; this is where I come from so they accept it on those terms more than they would an assessment given by a professional because they don't know what's going on there" (C. Crevier, 2007, Personal communication).

\section{Psychological Testing}

As indicated in the description of the services offered by BAN, psychological testing is used to assess clients for things like mental health, intelligence, and parenting capacity. The holistic understanding of human nature imbedded in the Medicine Wheel is not always compatible with the protocol of a psychological assessment and the type of reporting required by child welfare and the justice system to make their decisions. Dr. Hengen, a registered psychologist, combines the training and needs of the western establishment with the teachings of the Medicine Wheel by reporting on the test instruments he uses, their purpose and limitations and their findings within the holistic perspective of the Medicine Wheel by interpreting the test results within the socio-cultural context the clients find themselves.

The use of the Medicine Wheel as a of reference for taking case history and framing diagnoses on DSM-IV access one and associating reliable remedies and curative procedures mapping against such diagnoses insures that cultural differences are less likely to be misinterpreted as psychological deviances. As mentioned earlier in this paper, this lack of culturally sensitive diagnosis is argued to contribute to the over diagnosis of pathological conditions in Aboriginal People.

One of the counsellors (C. Crevier, 2007, personal communication) and the client (D. Michel, 2007, personal communication) interviewed for this paper suggested another difference in the way psychological testing is done at BAN as opposed to at mainstream psychological centres. They both talked about how counsellors in other centres didn't look at clients, didn't understand them and said things to the clients that the clients did not understand. The
BAN approach, based on the Medicine Wheel and respect for clients, removes, or at least reduces, this professional barrier while maintaining the quality of the psychological assessment and increasing its interpretative value.

\section{Assessment of Trauma}

In the second level of training BAN counsellors are taught that the Medicine Wheel can be used as an assessment tool to "harvest information about the client, especially about trauma or injury (instability) can be detected in matters of: the heart, the body, the head and the spirit. Each dimension has its own symptoms of injury or need for medicine:

- the heart (emotional): gets overloaded with strong feelings coming all at once; pain leads to fear, which leads to anger, which leads to hostility, which leads to guilt, which leads to more pain.

- the body (physical): gets both tired and edgy, oversensitive to noise and touch and light, but numb to comfort; diet changes, usually not for the better; stress is more physical than people realize.

- the head (mental): gets confused when stressful or crisis events occur; concentration is difficult, memory is lost, distractions happen easily; relationships suffer; social isolation and withdrawal (wounded go off and hide); thinking shuts down to a few automatic (kneejerk) reactions/habits; defensiveness takes over blaming, denying, projecting, avoiding, rationalizing the soul (spiritual): what a person respects is key to their spirit; the spirit that guides a person's life can be seen in the way they act more than in the way they talk (Hengen, 2006b, p. 16-18).

\section{Decision Making}

The Medicine Wheel is also used to organize the aspects of the decision making "executive control" functions of human behaviour.

- Emotional self control: directs and cues the use of feedback to strengthen, change and reduce or suppress emotional reactions.

- Motor self control: directs the use of motor abilities to translate thought into action and create tangible products.

- Mental self control: directs the selective getting, holding, manipulating, storing, and retrieving of information and action planning.

- Spirit (moral) self control: directs the use of emotional, physical and mental processes to construct visions of the future and plans for action over longer periods of time; reflects on the past to improve the present (Hengen, 2006a, p. 20.). 


\section{Going Back to the Roots: Using the Medicine Wheel in the Healing Process}

\section{Case Management}

BAN counsellors are taught that the Medicine Wheel as a case management tool which includes:

1. A chart or map of findings; problems or wounds in each area are identified; solutions and remedies (medicines) are found;

2. A plan is made to apply medicines to wounds for healing;

3. A plan which is managed by the client or learner, with help to learn how.

Counsellors are taught that they help create the plan, help to guide it at first, then turn it over to the client for maintenance by a series of steps that honour and support the process of adult learning (Hengen, 2006b, p.10).

\section{Summary and Conclusions}

The BAN program offers a significant service to Aboriginal and non Aboriginal persons living within and outside the core neighbourhood of Saskatoon. The Medicine Wheel is the key concept used and its use permeates the entire program. The Medicine Wheel provides a visual teaching and learning tool which ties the program and its participants to the traditional aboriginal worldview. Clients who leave the clinic with Medicine Wheel icon and its explanation report that they can use this knowledge to understand their thoughts and feelings between visits (Tom Hengen, personal communication, May 28, 2009). This helps them to develop and maintain a self directed lifestyle management plan.

Looking at the treatment process at BAN from a western social work perspective, BAN offers a culturally sensitive, supportive form of nondirective psychotherapy. Respect for the client, providing them a setting in which they can feel safe to face the issues they need to face, and providing them with the support they need to make changes are central to the service offered.

While the Medicine Wheel is a specific Aboriginal icon, it is presented at BAN as a learning and teaching tool rather than a religious or spiritual icon. Doing this makes it a tool that can be used by anyone who seeks services from the staff at BAN.

While many might know little or nothing of its meaning and significance, few people living in western Canada would not recognize the Medicine Wheel icon as a symbol of traditional Aboriginal culture. The values of living a balanced life and the clear visual representation of what that means provided by the Medicine Wheel is something that transcends cultures. For Aboriginal clients the Medicine Wheel provides the additional benefit of showing the importance and relevance of their traditional worldview, something that the euro-Canadian mainstream has been trying to denigrate and wipe out for over 100 years.

\section{References}

Aboriginal Healing Foundation. (2006). Final Report of the Aboriginal Healing Foundation: Volume two: Measuring Progress: Program Evaluation. Ottawa Ontario. Aboriginal Healing Foundation.

Building A Nation. (1998). Building A Nation-prospectus. Unpublished manuscript

Bruyere (2007). Making circles: Renewing first nations ways of helping. In Coates, J.; Graham, J.; Swartzentruber, B. with Ouellette, B. Spirituality and Social Work: Selected Canadian Readings, p 259-272. Toronto. Canadian Scholars Press.

Chansonneuve, D. (2007). Addictive Behaviours Among Aboriginal People in Canada. Ottawa. Aboriginal Healing Foundation.

Environment Canada. Aboriginal Traditional Knowledge and Environmental Management. Retrieved 20/07/2006 from http:/ www.wc.gc.ca/science/sandsept-02/printversion/print1_e. html.

Wesley-Esquimaux, CV. \& Smolewski, M. (2004). Historic Trauma and Aboriginal Healing. Ottawa. Aboriginal Healing Foundation.

Hengen, T. (2006a). Medicine Wheel Counselling and Case Management Training Package. Level 1. Building A Nation Training Institute.

Hengen, T. (2006b). Medicine Wheel Counselling and Case Management Training Package. Level 2. Building A Nation Training Institute.

Kemp. S.; Whittaker, J.; \& Tracy, E. (1997). Person-Environment Practice: The Social Ecology of Interpersonal Helping. Hawthorne, New York, Aldine De Gruyter, Inc.

Karls, J. \& Wanderi, K. (1994). Person-In-Environment System: The PIE classification System for Social Functioning Problems. Washington, D.C., National Association of Social Workers Press

Kirmayer, L.; Groleau, D.; Jaswant, J.; Blake, C.; \& Jarvis, E. (2003). Cultural consultation: A model of mental health service for multicultural societies. Canadian Journal of Psychiatry, 48(3), p. 145-153.

Kurtz, D., Nyberg, J., Van Den Tillaart, S., Mills, B. and The Okanagan Urban Aboriginal Health Research Collective (OUAHRC). (2009). Silencing of voice: An act of structural violence. Urban aboriginal women speak out about their experiences with health care. Journal of Aboriginal Health 4(1), p.55-63.

Lavallee, L (2009). Balancing the medicine wheel through physical activity. Journal of Aboriginal Health, 4(1), p.64-71.

Lemstra, M.; Neudorf, C. \&Opondo. (2006). Health Disparity By Neighbourhood Income. Saskatoon Health District. 


\section{First Peoples Child \& Family Review, Volume 4, Number 1, 2008}

McCormick, R. (1966). Culturally appropriate means and ends of counselling as described by the First Nations people in British Columbia. International Journal for the Advancement of Counselling, 18, p.163-172.

Montour, L. (1996). The Medicine Wheel: Understanding "Problem" Patients in Primary Care. Presented at the fifth annual meeting of the Native Physician Association in Canada. Ottawa, Ontario, August 23-25, 19956. Retrieved February 4, 2007 from http://xnet.kp.org/pemanentejournal/winter00pj/ wheel.html.

National Aboriginal Health Organization (2009). Cultural Competency and Safety: A Guide for Health Care Administrators, Providers and Educator. Retrieved May 29, 2009 from http://www.naho.ca/publications/ culturalCompetency.pdf.

Rollock, D. \& Gordon, E. (2000). Racism and mental health into the 21st century: Perspectives and parameters. American Journal of Orthopsychiatry, 70(1), p.5-13.

Thomas, R. (2006). Collecting stories, collecting culture: An integrated practicum report from a Building A Nation practicum January - June, 2006. Unpublished monograph, University of Regina Faculty of Social Work.

Van Hook, M. (2009). Social Work Practice with Families: A Resiliency Based Approach. Chicago IL, Lyceum Books Inc.

Waldram, J.; Innes, R.; Kaweski, M.; \& Redman, C. (2005) Building A Nation Inc.; A Models and Metaphors Research Project Case Study, Final Report. Ottawa Ontario. The National Network for Aboriginal Mental Health Research and Training. 